\title{
The Effect of Coaching Practices on Psychological Contract Fulfillment of Student-Athletes
}

Authors' contribution:
A) conception and design of the study
B) acquisition of data
C) analysis and interpretation of data
D) manuscript preparation
F) obtaining funding

\author{
Davar Rezania $^{1 \mathrm{~A}-\mathrm{E}}$, Robert Gurney ${ }^{2 \mathrm{~A}-\mathrm{E}}$ \\ ${ }^{1}$ University of Guelph, Canada \\ ${ }^{2}$ MacEwan University, Canada
}

ABSTRACT

We examine the relationships between coaching practices, psychological contract fulfillment and the impact it has on satisfaction and in-role behavior of studentathletes. We surveyed a total of 183 student-athletes in Canada. Utilizing Partial Least Squares path modeling algorithm, the results confirm that the extent of psychological contract fulfillment is positively related to satisfaction and role-behavior. In addition, practices of compensation, information sharing, and security (i.e. ensuring continuation of position on the team) are related to fulfillment of psychological contracts. However, the data does not provide support for the idea that training is related to the fulfillment of psychological contracts. The results suggest that universities can manage students-athletes' expectations by institutionalizing coaching practices that signal commitments for compensation, information sharing, and provide assurance of position on the team. Such practices have potential to improve the athlete's performance.

\section{KEYWORDS} psychological contract, social exchange, coaching and development, coach-athlete relationship

\section{Introduction}

The management of student-athletes in college/ university sports can be viewed as complex and involves multiple resource people and groups such as, sport governing bodies, athletic directors, team managers, coaches, officials, sports medicine support, university administration, student services, faculty, and program advisors. The subject has been studied in the past through investigations of diverse areas and topics (e.g. Gill, \& Farrington, 2014; Williams, 2011). Much of the responsibility of managing athletes is placed on the coach to set the desired tone through policies and practices. Coaching practices may act as signals or messages sent by a university for helping students to make sense of their student-athlete position. Kellett (1999) argues that a coach's activities are fundamentally social in nature and that coaches need training in social skills such as communication, counselling, empowering, group decision making and group facilitation. In sports coaching, craft is as important as sports psychology (Day, 2012). To further understand the relationship between the university and the athlete, it is perhaps important to understand the athlete's perceptions of how coaching practices impact their motivation and role behavior.

This interpersonal dynamic between the coach and the player is part of a social exchange and can be studied in the context of social exchange theory (Case, 1998). Social exchange theory describes how high- 
quality relationships between individuals develop (Blau, 1964). According to this theory, all human relationships are formed by the use of a subjective cost-benefit analysis and the comparison of alternatives. In contrast to relationships based purely on economic exchange, social exchange relationships involve obligations which cannot be specified ahead of time and require the parties to trust one another (Blau, 1964).

Psychological contracts are an especially important lens through which one is able to view how reciprocal exchanges of promises and obligations impact motivation and discretionary behavior that is not explicitly recognized by the formal reward systems (Organ, 1997; Robinson, \& Morrison, 1995). The concept of psychological contracts has been used to study the terms of the social exchange relationship that exists between employees and their organizations (Argyris, 1960; Robinson, \& Morrison, 1995, 2000; Wayne, Shore, \& Liden, 1997). Psychological contracts consist of the obligations that employees believe their organization owes them something and the obligations the employees believe they owe their organization in return (Rousseau, 1995). The 'owing' notion consists of the voluntary actions that each party engages in with the belief that the other party will reciprocate in return (Rousseau, \& Parks, 1992). When employees perceive that their psychological contract has been fulfilled, they may attempt to reciprocate by increasing their contributions to the organization (Wayne et al., 1997) and employee motivation may increase (Lee et al., 2011). Job satisfaction is promoted when promises are kept, while promises that are not kept tend to produce negative emotions and poor relationships (Zhao, Wayne, Glibkowski, \& Bravo, 2007).

Although many studies have considered the effect of leader-member exchanges on coaching effectiveness, there seems to be only a few studies investigating the concepts of psychological contracts in coach-athlete relationships. Barnhill's (2011) doctoral dissertation integrated traditional concepts and definitions of psychological contracts into examinations of perceived breaches of psychological contracts in inter-collegiate student-athletes. Barnhill, \& Turner (2013) found that student-athletes had intentions to depart from their respective teams, as responses to perceptions of psychological contract breaches and violations. In this paper, we consider the fulfilment of psychological contract as a construct against which to evaluate the perceptions of university-athletes views of their coaches. Indeed, student-athlete's motivation and rolebehaviour may be supported by the formation of psychological contracts between the coach and athletes. We thus seek to explore the role of psychological contracts on athletes' motivation, satisfaction, and role behaviour.

\section{Coach-athlete relationship}

There is agreement that a relationship exists between the quality of the coach-athlete relationship and success in coaching sports (Lyle, 2002), and that a healthy relationship requires interpersonal qualities such as trust, respect, commitment, understanding, and passion (e.g. Greenleaf, Gould, \& Dieffenbach, 2001; Cockerill, 2003; Rezania, \& Gurney, 2014). Coach-athlete relationships influence the athletes' and coaches' well-being (Smith, \& Smoll, 1990), and; is an element of coaching leadership effectiveness (Chelladurai, 1990). Coaching behaviors influences the satisfaction, motivation, self-esteem, enjoyment, and intention to continue participating in sport (Conroy, \& Coatsworth, 2006; Scanlan, \& Lewthwaite, 1986). Jackson, Grove, and Beauchamp (2010) indicate that athletes who reported moderate to high levels of relationship perception with their coaches were more satisfied with their personal treatment, training and instruction in comparison to athletes illustrating low and unfulfilled relationship perceptions with their coaches.

Social exchange theory has been used to explain behavior in diverse areas of relationship between the coach and athletes such as athletic satisfaction and inter-team communication (Weiss, \& Stevens, 1993; Sullivan, Gee, 2007). It is expected that when a student-athlete is aware and accepts the coaches' values, support and contributions to the team, then the student-athlete is inclined to reciprocate by putting forth greater effort and performance. Consistent with the predictions of social exchange theory, student-athletes' contributions to the team may increase, as the coach provides more than they originally agreed to provide. We expect that when psychological contracts are fulfilled, the student-athletes are more likely to be satisfied, motivated, and behave in ways that promote team performance. We hypothesize then, that the extent of 
psychological contract fulfillment will be positively related to the student-athlete's level of motivation, satisfaction and in-role behavior.

H1: Psychological contract fulfillment is significantly associated with satisfaction.

$\mathrm{H} 2$ : Psychological contract fulfillment is significantly associated with in-role behavior.

\section{Coaching practices}

Coaching practices entail numerous responsibilities, such as the process of recruitment and selection of team members, training athletes, providing feedback and rewards to motivate student-athletes. Coaches are often faced with making choices regarding the extent to which they decentralize authority and leadership. There is acknowledgement that managers can differ in their approach towards managing their teams (e.g. a focus on control or commitment) and that commitment oriented approaches outperform control oriented approaches (e.g. Arthur, 1992, 1994). Arthur (1992/1994) indicates that a commitment maximizing system that encourages discretionary employee efforts, a way to attract, motivate and retain qualified employees committed to the goals of an organization outperforms a cost reduction system that aims at reducing direct labor cost and other employment-relations expenditures (see also Guest, 1997; Williams, \& Anderson, 1991). Appelbaum et al. (2000) in their study towards High Performance Work Systems report that work systems that support high performance include rigorous selection, better training of skills and abilities, comprehensive incentives to enhance motivation, and participative structures that improve the opportunity to contribute (see also MacDuffie, 1995; Osterman, 1994; Huselid, 1995).

In general there is agreement that organizations that focus on commitment oriented practices pay attention to and invest in their employees. Such practices are aimed at motivation of employees by increasing their skills, motivation, and involvement. Practices such as information sharing, training and development, compensation can help the formation of a positive psychological contact (Rousseau, 1995). Such practices send structural signals about the contract.

In line with the predictions psychological contract literature, we hypothesize that commitment oriented coaching practices of compensation, security, training, and information sharing will be positively related to the student-athlete's perception of fulfillment of psychological contract.

H3: Compensation is significantly associated with psychological contract fulfillment.

H4: Security is significantly associated with psychological contract fulfillment.

H5: Training is significantly associated with psychological contract fulfillment.

H6: Information sharing is significantly associated with psychological contract fulfillment.

\section{Measures}

We adapted a questionnaire developed by Abdullah (2011), based on the previous work of Robinson and Morrison (2000), Williams, and Anderson (1991) and others. In the first stage, a student-athlete, who was working as a research assistant, adapted the questionnaire to the context of the relation between the coach and student-athletes. The questionnaire was further reviewed by two faculty members and an Athletic Director from participating universities to ensure that ambiguous, vague and unfamiliar terms were not included. Items were adjusted where necessary. A seven item Likert scale was used ( $1=$ strongly disagree, $7=$ strongly agree) to capture student-athletes' extent of agreement with each statement. The following is a sample of questions on the questionnaire:

I feel I am adequately funded compared to other student-athletes here at this university.

I have received everything promised to me in exchange for my contributions.

Almost all of the promises made by my coach have been kept so far. 
My coach keeps me informed and up-to-date about important issues concerning me as a studentathlete.

I perform as a student-athlete above and beyond the call of duty.

I adequately complete assigned student-athlete tasks that my coach gives me.

My coach regularly assures me that if I perform modestly I will not get cut from the team.

I receive from my coach the training I need to do well as a student-athlete.

Research assistants took the survey to the teams and provided envelopes for the respondents to submit their completed questionnaire in and return it to the research assistants. The questionnaire was distributed among 401 student-athletes from two universities. A total of 183 questionnaires were correctly completed by those in a team sports. The returned questionnaires revealed 71 females, 112 males; ages were between 18 and 23 years. The completed questionnaires reflected student-athletes from nine different sports, hockey, soccer, basketball, volleyball, curling, baseball, golf, swimming, and football.

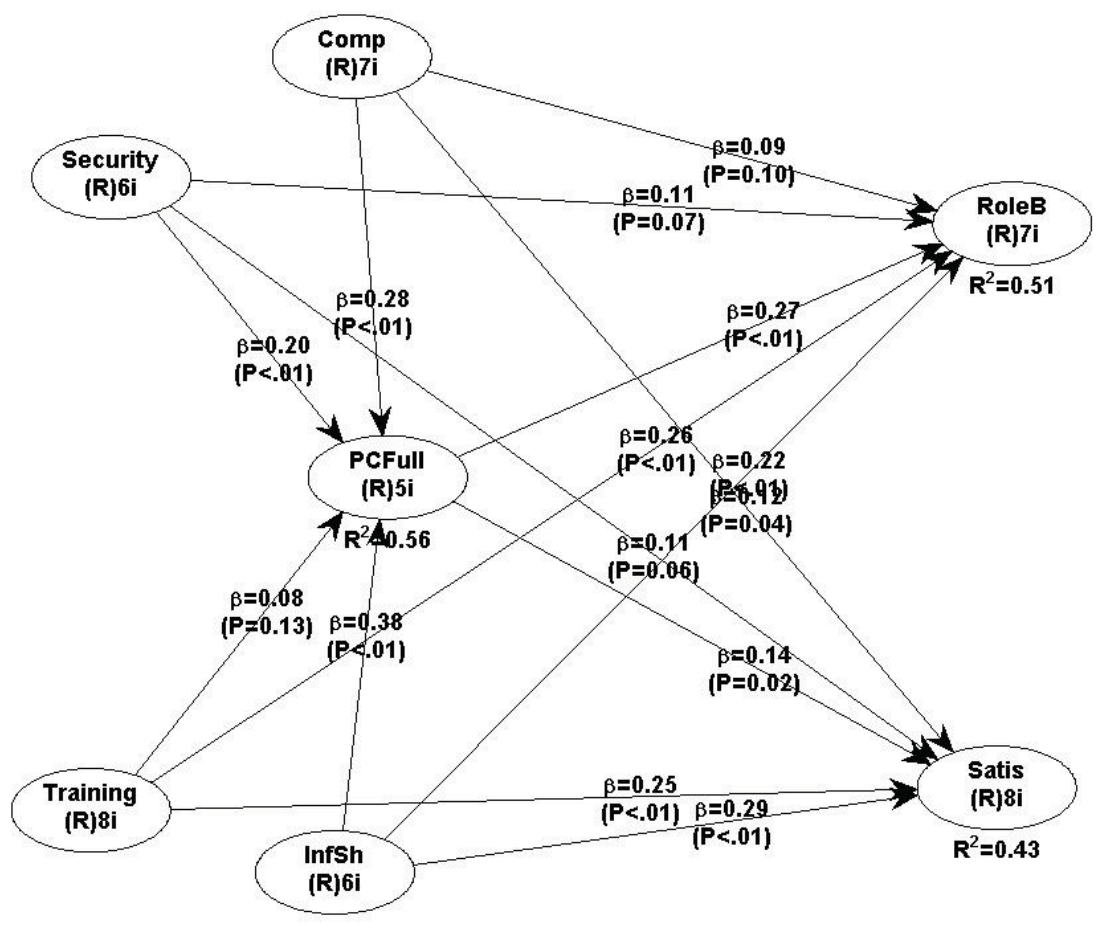

Figure 1. Path model

Source: own study.

We utilized Partial Least Squares (PLS) path modeling algorithm (Hulland, 1999) implemented in WarpPLS (Kock, 2012). Figure 1 presents the path model. For factor analysis of the measurement model, we observe that the loadings of items on the latent constructs are higher than 0.7 , and all items loaded significantly on their respective factors which implies indicator reliability. Table 1 presents latent variable coefficient. Full collinearity VIFs are lower than the threshold 3.3, indicating that the model is free from common method bias. Composite reliability, Cronbach's alpha, and average variance extracted (AVE) have values greater than the minimum threshold which implies convergent validity of constructs (Hair Jr, Hult, Ringle, \& Sarstedt, 2013). We also observe that in Table 2, the square root of AVE exceeds the correlations between the factors making each pair, indicating discriminant validity (Fornell, \& Larcker, 1981). 
Table 1. Latent variable coefficients

\begin{tabular}{lccccccc}
\hline & Comp & Security & Training & InfSh & PCFull & RoleB & Satis \\
\hline R-squared & & & & & 0.56 & 0.511 & 0.43 \\
Composite reliability (desired $>\mathbf{0 . 7 0})$ & 0.91 & 0.92 & 0.97 & 0.95 & 0.98 & 0.94 & 0.93 \\
Cronbach's alpha (desired $>\mathbf{0 . 7 0})$ & 0.88 & 0.89 & 0.97 & 0.93 & 0.98 & 0.93 & 0.92 \\
AVE (desired $>\mathbf{0 . 5 0 )}$ & 0.60 & 0.64 & 0.81 & 0.75 & 0.91 & 0.69 & 0.64 \\
Full collinearity VIFs (desired $<\mathbf{3 . 3})$ & 1.56 & 1.47 & 1.80 & 2.68 & 2.07 & 1.77 & 1.64 \\
Q-squared (desired $>\mathbf{0}$ ) & & & & & 0.56 & 0.46 & 0.37 \\
\hline
\end{tabular}

Source: own study.

Table 2. Correlations among 1.vs. with sq. rts. of AVEs shown on diagonal

\begin{tabular}{lccccccc}
\hline & Comp & Security & Training & InfSh & PCFull & RoleB & Satis \\
\hline Comp & 0.77 & & & & & & \\
Security & 0.31 & 0.80 & & & & & \\
Training & 0.44 & 0.33 & 0.90 & & & & \\
InfSh & 0.52 & 0.48 & 0.62 & 0.87 & & & \\
PCFull & 0.52 & 0.49 & 0.49 & 0.66 & 0.95 & & \\
RoleB & 0.20 & 0.43 & 0.47 & 0.54 & 0.44 & 0.83 & 0.80 \\
Satis & 0.27 & 0.39 & 0.44 & 0.54 & 0.43 & 0.54 & 0.84 \\
\hline
\end{tabular}

Source: own study.

The model displays $\mathrm{R}^{2}$ values of 0.56 for PCF (i.e. $51 \%$ of variance in psychological contract fulfillment is explained by coaching practices), 0.43 for satisfaction, and 0.51 for role behavior ( $\%$ of variance in each is explained by psychological contract fulfillment and the coaching practices). Table 3 reports the total effects and p-values obtained from the nonparametric bootstrapping procedure (Chin, 1998) using 100 subsamples to evaluate the statistical significance of each path coefficient.

Table 3. Total effect, p-value for paths from column label to row

\begin{tabular}{lccccc}
\hline & Comp & Security & Training & InfSh & PCFull \\
\hline PCFull & $0.279,<0.001$ & $0.204,0.002$ & $0.084,0.126$ & $0.384,<0.001$ & \\
RoleB & $0.167,0.01$ & $0.161,0.013$ & $0.283,<0.001$ & $0.32,<0.001$ & $0.267,<0.001$ \\
Satis & $0.165,0.011$ & $0.141,0.026$ & $0.259,<0.001$ & $0.345,<0.001$ & $0.143,0.024$ \\
\hline
\end{tabular}

Source: own study.

By looking at Table 2 it is interesting to note that in this study with the exception of $\mathrm{H} 5$ all hypotheses are supported.

\section{Discussion and practical implications}

Krawczyk (2009) call for ways to diversify research approaches to understanding coach-athlete relationships. Our study contributes to the current literature in two ways. First, it contributes to the literature on coach-athlete relationships by applying the concept of psychological contracts. This extends the current research that considers how social exchange theory shapes the relationship between the coach and athlete. Second, this study extends prior research on psychological contracts by looking at the context of studentathletes and their relationship with their coach. Most of the prior research has focused on the psychological contract between an organization and its employees. As noted in the introduction of this study, the Human Resources Management literature reports a strong relationship between fulfillment of psychological contracts and behavioral outcomes. In line with such reports, the present study was designed to determine the effect of fulfillment of psychological contracts on in-role behavior, and satisfaction of student-athletes. The results confirm the relationship as expected. Thus, consistent with the premises of social exchange theory, it appears that team members (student-athletes) whose psychological contracts have been fulfilled are most likely to be satisfied, motivated, and willing to do more than is required. 
Given that very little was found in the literature about the role of psychological contract fulfillment in the context of coaching student-athletes, the presented results are encouraging and have important implications for developing coaching practices that lead to the fulfillment of psychological contracts.

The results suggest that, at least among the individuals in this study, it appears that student-athletes' perceptions of the extent to which their coach has showed their commitments for compensation, to share information and provide assurance of position on the team are a more important predictor of their perception of their fulfillment of psychological contracts than are their perceptions regarding the extent to which their coach has behaved regarding training and development.

Why should the effect of training and development not be strong? One possible explanation may lie in the fact that student-athletes have a special arrangement with their university. Rousseau (2004) points out that when workers have negotiated special employment arrangements not available to others, they are more likely to believe they have relational contracts. Student-athletes have special opportunities for training and development not available to other students. Such 'idiosyncratic deals' do not have particularly powerful effects on the psychological contract when created during the recruiting process (Rousseau, 2004). Studentathletes who get these special arrangements during recruitment may attribute these to their market value. As such, they do not see it as signaling something special about their coach.

Another possible explanation is that student-athletes shape their psychological contracts through their career goals. They may not see their relationship with their coach or the university as a long-term employment possibility but merely as a stepping stone to better opportunities elsewhere. Literature on psychological contracts indicate that people with such perspective tend to adopt a more transactional view of employment, while those seeking longer-term employment tend to embrace relational contracts (Rousseau, 2004). This may provide an explanation for our observation that compensation and security, which are transactional signals, have a strong effect on the fulfillment of psychological contracts among participants in this study, while relational signals such as training and development do not impact psychological contract fulfillment.

As Short, and Short (2005, p. 29) state, a coach needs to "fulfill five defined roles - those of teacher, organiser, competitor, learner, and friend and mentor". The results of our study indicate the importance of three coaching practices that lead to satisfaction, motivation, and willingness to do more, mediated by the fulfillment of psychological contracts. The organizing role of the coach should therefore include practices that provide perceptions of fair compensation, and security of team membership. First, a coach should regularly provide assurance that the student-athlete position on the team is secure. A coach should regularly reinforce his/ her commitment to providing opportunity of participation on the sports team and that as long as the athlete is meeting the minimum academic and performance requirements, he/ she will not get cut from the team. In short, the student athlete should have the feeling that his/ her position on the team is secure and is of prime importance to the coach.

Second, the organizing role of a coach should include practices that inform the student-athletes about the compensation they receive. The athletic bursaries/ scholarships offered should be a competitive match to the student-athletes' athletic performance and/or criteria that has been informed and understood. Studentathletes should be fairly funded compared to other student-athletes at the university or at other universities, and/ or informed to potential funding opportunities and availability based on informed set criteria. Studentathletes should receive fair funding benefits that are linked to athletic performance.

As a friend and mentor, a coach should focus on information sharing. The student-athlete should generally feel well informed by the coach about changes that affect them or about important issues concerning their role as a student-athlete. They should also have a complete understanding of what is expected of him/ her in the student-athlete position and receive adequate and honest feedback. Student-athletes should be effectively facilitated to the information resources needed to perform to their best abilities as a student-athlete. 


\section{Limitation and proposals for further studies}

There are areas that need to be addressed in future research on the signaling value of coaching practices for psychological contract fulfillment. First, our findings are limited in terms of the sample. We only surveyed participants from two universities in one province in Canada. This had the advantage that the rules and policies around admission and compensation were similar in both universities. We realize that further studies should include teams from more universities across the country.

Second, in this study we utilized a measure of psychological contract fulfillment. Research on psychological contract often utilizes measures of psychological contract breach. Repeating this study, using a measure of psychological contract breach, would complement this study.

More research needs to examine how the psychological contract is formed. For example, student-athletes may perceive the promises made by the recruiters or admission personnel as more important than those made by their coach. Thus, they may respond differently when breaches arise regarding the behavior of their coach. Student-athletes may also respond differently to approaches to compensation, information sharing, and security. For example, a future study could look at the effectiveness of a constructivist approach to information sharing and team coaching (Rezania, \& Lingham, 2009) for the fulfillment of psychological contracts.

\section{REFERENCES}

Abdullah, A.B.M. (2011). The Role of Cultural Context and Psychological Contract on Workforce Management in the Multinational Corporations Operating in Emerging Markets. University of South Australia.

Argyris, C. (1960). Individual Actualization in Complex Organizations. Mental Hygiene, 44(2), 226-237.

Arthur, J.B. (1992). The link between business strategy and industrial relations systems in American steel minimills. Industrial and Labor Relations Review, 3(45), 488-506. DOI: 10.1177/001979399204500306

Arthur, J.B. (1994). Effects of human resource systems on manufacturing performance and turnover. Academy of Management Journal, 3(37), 670-687. DOI: 10.2307/256705

Barnhill, C.R. (2011). An Examination of the Antecedents and Outcomes of Psychological Contract Violation of Intercollegiate Student-Athletes. $(\mathrm{PhD}), \quad$ Ohio State University. Retrieved from: http://rave.ohiolink.edu/etdc/view?acc_num $=$ osu1311864418

Barnhill, C.R., \& Turner, B.A. (2013). Broken Promises: The Effect of Psychological Contract Violation on StudentAthlete Trust and Intentions to Leave Their Team. Journal of Intercollegiate Sport, 6(2), 179-195.

Blau, P.M. (1964). Exchange and Power in Social Life. New Brunswick USA, and London UK: Transaction Books.

Case, R. (1998). Leader Member Exchange Theory and sport: possible applications. Journal of Sport Behavior, 21(4), 387-395.

Chelladurai, P. (1990). Leadership in sports: A review. International Journal of Sport Psychology, 21(4), 328-354.

Conroy, D.E., \& Coatsworth, J.D. (2006). Coach training as a strategy for promoting youth social development. Sport Psychologist, 20(2), 128-144.

Day, D. (2012). 'Magical and fanciful theories': sports psychologists and craft coaches. Sports Coaching Review, 1(1), 5266. DOI: $10.1080 / 21640629.2012 .702468$

Fornell, C., \& Larcker, D.F. (1981). Structural equation models with unobservable variables and measurement error: Algebra and statistics. JMR, Journal of Marketing Research (pre-1986), 18(3), 382-382.

Green, K.W., Wu, C., Whitten, D., \& Medlin, B. (2006). The impact of strategic human resource management on firm performance and HR professionals' work attitude and work performance. International Journal of Human Resource Management, 17(4), 559-579. DOI: 10.1080/09585190600581279

Greenleaf, C., Gould, D., \& Dieffenbach, K. (2001). Factors influencing Olympic performance: interviews with Atlanta and Negano US Olympians. Journal of Applied Sport Psychology, 13(2), 154-184. DOI: 10.1080/104132001753149874

Guest, D.E. (1997). Human resource management and performance: a review and research agenda. International Journal of Human Resource Management, 8(3), 263-276. DOI: 10.1080/095851997341630 
Hair Jr, J.F., Hult, G.T., Ringle, C., \& Sarstedt, M. (2013). A primer on partial least squares structural equation modeling (PLS-SEM). Thousand Oaks, California: SAGE Publications, Incorporated.

Hulland, J. (1999). Use of partial least squares (PLS) in strategic management research: a review of four recent studies. Strategic Management Journal, 20(2), 195-204. DOI: 10.1002/(SICI)1097-0266(199902)20:2<195::AIDSMJ13>3.0.CO;2-7

Jackson, B., Grove, J.R., \& Beauchamp, M.R. (2010). Relational efficacy beliefs and relationship quality within coachathlete dyads. Journal of Social and Personal Relationships, 27(8), 1035-1050. DOI: 10.1177/0265407510378123

Kellett, P. (1999). Organisational leadership: Lessons from professional coaches. Sport Management Review, 2(2), 150171. DOI: 10.1016/S1441-3523(99)70094-X

Kock, N. (2012). WarpPLS 5.0 User Manual. ScriptWarp Systems. Laredo, Texas.

Krawczyk, Z. (2009). Theoretical Conceptions in Sport Social Sciences. Physical Culture and Sport. Studies and Research, 47(1), 5-10. DOI: 10.2478/v10141-009-0026-9

Lee, C., Liu, J., Rousseau, D.M., Hui, C., \& Chen, Z.X. (2011). Inducements, contributions, and fulfillment in new employee psychological contracts. Human Resource Management, 50(2), 201-226. DOI: 10.1002/hrm.20415.

Lyle, J. (2002). Sports coaching concepts: A framework for coaches' behaviour. London: Routledge.

Organ, D.W. (1997). Organizational citizenship behavior: It's construct clean-up time. Human Performance, 10(2), 8597. DOI: $10.1207 /$ s15327043hup1002_2

Rezania, D., \& Gurney, R. (2014). Building successful student-athlete coach relationships: examining coaching practices and commitment to the coach. SpringerPlus, 3(1), 383. DOI: 10.1186/2193-1801-3-383

Rezania, D., \& Lingham, T. (2009). Towards a method to disseminate knowledge from the post project review. Knowledge Management Research \& Practice, 7(2), 172-177. DOI: 10.1057/kmrp.2009.9

Robinson, S.L., \& Morrison, E.W. (1995). Psychological contracts and ocb - the effect of unfulfilled obligations on civic virtue behavior. Journal of Organizational Behavior, 16(3), 289-298. DOI: 10.1002/job.4030160309

Robinson, S.L., \& Morrison, E.W. (2000). The development of psychological contract breach and violation: A longitudinal study (p. 529). Journal of Organizational Behavior, 21(7), 525-546. DOI: 10.1002/10991379(200008)21:5<525::AID-JOB40>3.0.CO;2-T

Rousseau, D.M. (1995). Psychological Contracts in Organizations. Thousand Oaks, California: SAGE Publications, Incorporated.

Rousseau, D.M. (2004). Psychological Contracts in the Workplace: Understanding the Ties That Motivate. The Academy of Management Executive, 18(1), 120-127. DOI: 10.5465/AME.2004.12689213

Rousseau, D.M., \& Parks, J.M. (1992). The Contracts of individuals and organizations. Research in Organizational Behavior, 15(1), 1-43.

Scanlan, T.K., \& Lewthwaite, R. (1986). Social psychological aspects of competition for male youth sport participants: IV. Predictors of enjoyment. Journal of Sport Psychology, 8(1), 25-35.

Short, S.E., \& Short, M.W. (2005). Essay: Role of the coach in the coach-athlete relationship. Lancet, 366(1), 29-30. DOI: $10.1016 / \mathrm{S} 0140-6736(05) 67836-1$

Smith, R.E., \& Smoll, F.L. (1990). Self-esteem and children's reactions to youth sport coaching behaviors: A field study of self-enhancement processes. Developmental psychology, 26(6), 987-993. DOI: 10.1037/0012-1649.26.6.987

Wayne, S.J., Shore, L.M., \& Liden, R.C. (1997). Perceived organizational support and leader-member exchange: A social exchange perspective. Academy of Management Journal, 40(1), 82-111.

Weiss, M.R., \& Stevens, C. (1993). Motivation and attrition of female coaches: An application of social exchange theory. The Sport Psychologist, 7(3), 244-261.

Williams, L.J., \& Anderson, S.E. (1991). Job Satisfaction and Organizational Commitment as Predictors of Organizational Citizenship and In-Role Behaviors. Journal of Management, 17(3), 601-617. DOI: $10.1177 / 014920639101700305$

Williams, R. (2011). ATLAS: A Community Policing Response to Adverse Student Athlete Behavior. Campus Law Enforcement Journal, 41(1), 21-23. 
Zhao, H., Wayne, S.J., Glibkowski, B.C., \& Bravo, J. (2007). The impact of psychological contract breach on workrelated outcomes: A meta-analysis. Personnel Psychology, 60(3), 647-680. DOI: 10.1111/j.1744-6570.2007.00087.x

\section{AUTHOR'S ADDRESS: $\quad$ Davar Rezania}

Department of Management

College of Business and Economics

University of Guelph

50 Stone Rd E, Guelph, Ontario

N1G 2W1, Canada

E-mail: drezania@uoguelph.ca

Received: 20 February 2016; Accepted: 10 May 2016 